\title{
Energy \&

\section{Room-temperature sodium-ion batteries: Improving the rate capability of carbon anode materials by templating strategies $\uparrow$}

\author{
Received 16th May 2011, Accepted 10th June 2011 \\ DOI: 10.1039/c1ee01744f
}

Sebastian Wenzel, Takeshi Hara, Jürgen Janek and Philipp Adelhelm*
Graphite, the standard anode material in current lithium-ion batteries, is not suited for a sodium based system, as Na hardly forms staged intercalation compounds with graphite. ${ }^{10}$ This is different from non-graphitic carbons and it is suggested that the storage mechanisms for $\mathrm{Na}$ and $\mathrm{Li}$ are similar, although the capacity is smaller in the case of sodium. ${ }^{11}$ Several types of non-graphitic carbon materials have been tested and capacities between 100 and $300 \mathrm{~mA} \mathrm{~h} \mathrm{~g}^{-1}$ under differing conditions were found. ${ }^{11-16}$ Although these capacities are promising, the cells were only cycled for a few times and, more importantly, could be only obtained at extremely low currents (typically $C$-rates between $C / 70$ and $C / 80$ ) or at elevated temperatures $\left(\geq 60{ }^{\circ} \mathrm{C}\right)$, which indicates very sluggish kinetics for the sodium storage process (Table $\mathrm{S} 1 \dagger$ ). Thus alternative carbon materials are needed in order to achieve satisfying performance at room temperature and at higher currents.

For lithium insertion, it is known that fast kinetics and high capacity can be achieved by introducing nanoporosity and a hierarchical pore system into the anode. ${ }^{17}$ Such systems are accessible via the nanocasting route, utilizing porous silica materials as templates. ${ }^{18}$

In this work we show as a proof of principle that this concept is also applicable to sodium and that high capacities can be achieved at room temperature at high currents (e.g. C-rate of C/5, i.e. 15 times faster than $C / 75$ ), while also exhibiting long cycling stability. The outstanding performance of the templated carbon is illustrated by comparing with several commercially available porous carbon materials and non-porous graphite as reference.

Table 1 summarizes the surface areas and pore volumes of the different carbon materials used. The commercial reference carbon materials were exclusively microporous (activated carbon), or

\section{Broader context}

Currently there is an overwhelming interest in lithium-ion battery technology due to the need for efficient, light weight, safe and cost effective electrical energy storage systems. However, there is also a controversial discussion on the long term availability and geological distribution of lithium. Despite the fact that "sodium-ion batteries" could be based on an electrochemistry similar to Liion batteries, to date no workable system exists that allows satisfying operation at room temperature. Carbon materials are known to be suitable anode materials in lithium-ion batteries, but the few reports on their use in a sodium-ion cell are rather disappointing so far. In this work, we show as a proof of principle that current limitations can be successfully tackled by using engineered ("templated") carbon materials that can be easily synthesized by the nanocasting process and reasonable capacities can be obtained at high currents. As the nanocasting process allows the synthesis of many structured materials, our results further encourage research in the field of sodium-ion batteries. 
Table 1 Properties of the carbon materials as determined by nitrogen physisorption

\begin{tabular}{|c|c|c|c|}
\hline Name & $\begin{array}{l}\text { Surface area }{ }^{a} / \\
\mathrm{m}^{2} \mathrm{~g}^{-1}\end{array}$ & $\begin{array}{l}\text { Pore volume }{ }^{b} / \\
\mathrm{cm}^{3} \mathrm{~g}^{-1}\end{array}$ & $\begin{array}{l}\text { Dominant } \\
\text { porosity }\end{array}$ \\
\hline Graphite & 6 & 0.044 & Nonporous \\
\hline Timrex 100 & 118 & 0.298 & $\begin{array}{l}\text { Micro-, meso-, and } \\
\text { macroporous }\end{array}$ \\
\hline Timrex 300 & 285 & 0.712 & \\
\hline Timrex 500 & 490 & 1.008 & \\
\hline $\begin{array}{l}\text { Activated } \\
\text { carbon }\end{array}$ & 1041 & 0.663 & Microporous \\
\hline $\begin{array}{l}\text { Templated } \\
\text { carbon }\end{array}$ & 346 & 0.798 & Meso- and macroporous \\
\hline
\end{tabular}

exhibited broad pore size distributions in the micro-, meso- and macropore range with surface areas between $118 \mathrm{~m}^{2} \mathrm{~g}^{-1}$ and $1041 \mathrm{~m}^{2}$ $\mathrm{g}^{-1}$. To study the impact of the surface area on the degree of $\mathrm{Na}$ insertion, three carbons from the same series (Timrex series) with differing surface areas were purchased. Using the same type of carbon ensures that other effects originating from the precursor (impurities, microstructure, etc.) are minimized. The nonporous graphite served as reference that should be mostly inactive regarding sodium insertion. The templated carbon was prepared by the nanocasting process using hierarchical porous silica as template and mesophase pitch as carbon precursor. The silica template was infiltrated by mesophase pitch dissolved in THF, dried and carbonized. The final carbon material was obtained by dissolution of the silica template in HF solution.

\section{a}

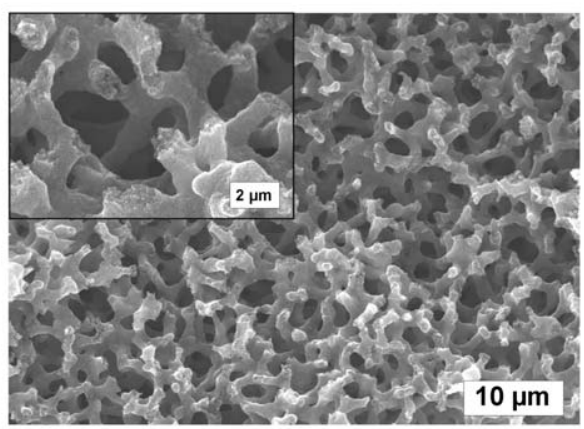

b

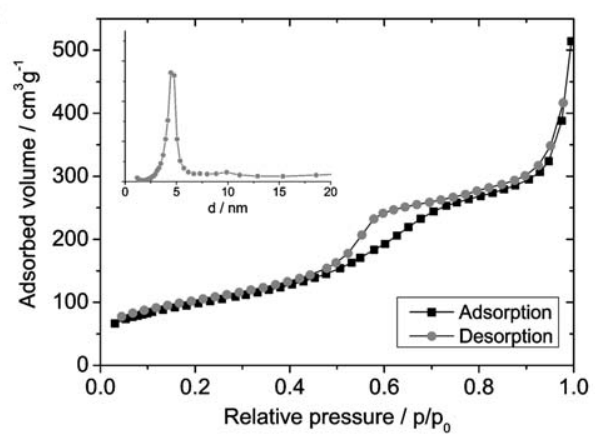

Fig. 1 (a) SEM image of the macroporous interconnected pore structure. (b) Isotherm and pore size distribution (BJH desorption branch) derived from nitrogen physisorption.
In contrast to the commercial carbons, the templated carbon exhibits a hierarchical pore system with defined, interconnected pores in the macro- and mesopore range, enabling fast ion transport and short diffusion lengths. Fig. 1 shows a SEM image of the interconnected macropore system with pores in the range $2 \mu \mathrm{m}-4 \mu \mathrm{m}$. The defined mesopore size is extracted from the nitrogen physisorption isotherm. A defined maximum in the pore size distribution is found at $5 \mathrm{~nm}$, derived from the desorption branch (BJH model). The offset at low relative pressures also indicates the presence of a minor amount of microporosity.

Electrochemical measurements were performed using a 3-electrode Swagelok type cell; metallic sodium was used as counter and reference electrode. Cells were cycled galvanostatically at room temperature at a rate of $C / 5$. An additional potentiostatic step at $1.6 \mathrm{~V}$ was added during Na-deinsertion until the current dropped below $2 \times$ $10^{-3} \mathrm{~mA}$ to allow equilibration of the system. ${ }^{19}$ The overall shape of the voltage profile was similar for all porous carbons, as illustrated by two samples with similar surface area (Timrex 300 and templated carbon, Fig. 2). Upon first insertion, the profiles show a step between $0.5 \mathrm{~V}$ and $0.75 \mathrm{~V}$ that originates from solid electrolyte interphase (SEI) formation, resulting in significant irreversible capacities. This behaviour is typical for non-graphitic carbons and well known from $\mathrm{Li}$ insertion, especially for (pitch based) soft carbon materials, and is mainly due to irreversible reactions between the electrolyte, the carbon material and the carbon surface groups upon first insertion. ${ }^{20,21}$ Once a stable SEI has formed, it hinders further reaction between the electrode and the electrolyte. However a large degree in irreversible capacity is also detrimental, as in a practical cell this loss needs to be compensated by additional cathode material. But it is worth noting that the irreversible capacity for $\mathrm{Li}$ insertion is larger for the same type of carbon (decrease from $527 \mathrm{~mA} \mathrm{~h} \mathrm{~g}^{-1}$ to $100 \mathrm{~mA} \mathrm{~h}$ $\mathrm{g}^{-1}$ for $\mathrm{Li}$ insertion in Timrex 500 compared to $250 \mathrm{~mA} \mathrm{~h} \mathrm{~g} \mathrm{~g}^{-1}$ to $50 \mathrm{~mA} \mathrm{~h} \mathrm{~g}$ for $\mathrm{Na}$ insertion, for example). This was also reported earlier ${ }^{13,14}$ and indicates that SEI formation for both alkali metals is different. Nevertheless, strategies in analogy to Li-ion batteries could be envisaged in order to reduce the degree in irreversible capacity. These include pre-conditioning of the carbon material or variation in electrolyte compositions (including additives), for example. ${ }^{22-29}$ Studies by Lu and Chung on pitch based carbon materials suggest that the irreversible capacity can be reduced by heat treatment under reductive $\mathrm{H}_{2}$ atmosphere, for example. ${ }^{30}$ A comprehensive study on the effect of surface treatment and screening of other possible electrolyte compositions is, however, outside the scope of this manuscript.

A linear relation between irreversible capacity and surface area is only found for the carbons of the same type (Timrex series), thus SEI formation is also influenced by other factors such as pore structure, carbon microstructure or impurities (Fig. S1 $\dagger$ ). Upon prolonged cycling, the reversible capacities stabilize and the charge/discharge curves show a sloped profile (Fig. 2b). Thus the insertion mechanisms are similar for the samples investigated.

The origin of the sloping profile and the mechanisms of $\mathrm{Na}$ insertion are discussed by Billaud et al. and Dahn et al. and relate, similar to Li, to several effects such as insertion, adsorption on the graphene sheets or interaction of sodium with impurity atoms. ${ }^{11,15}$

The important point of this work, however, is the significantly larger reversible capacity that is found for the templated carbon compared to the commercial carbons, reaching around $130 \mathrm{~mA} \mathrm{~h} \mathrm{~g}^{-1}$ after the first cycle at $C / 5$. This capacity corresponds to a nominal 
a

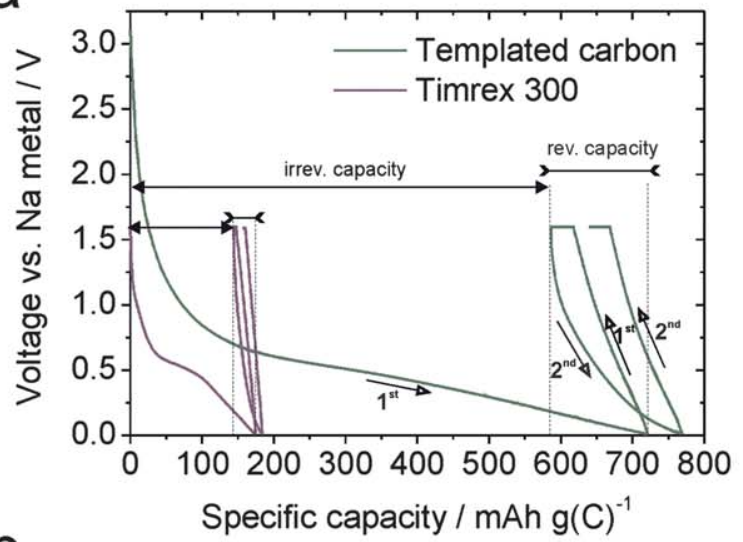

b
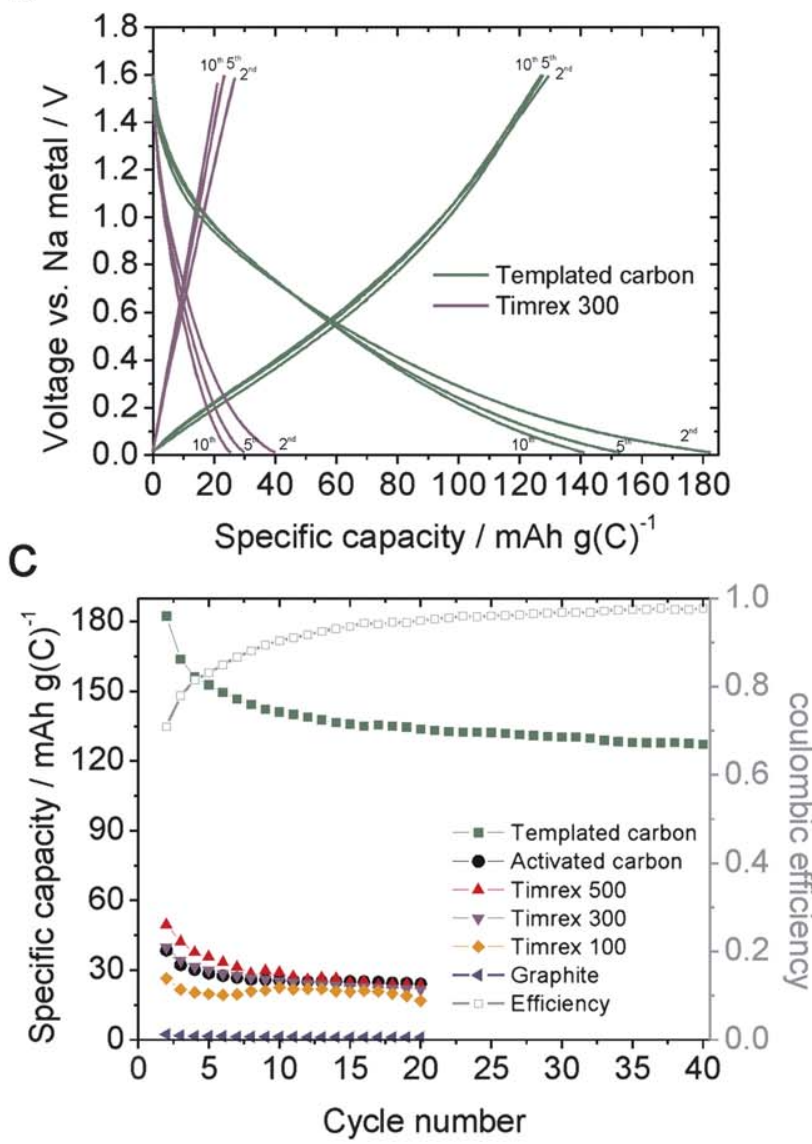

Fig. 2 ( $a$ and b) Charge/discharge curves for two carbon materials with similar surface area. (a) $1^{\text {st }}$ and $2^{\text {nd }}$ cycle; reversible and irreversible capacities for the first cycle (Na-insertion and $\mathrm{Na}$-deinsertion) are indicated for both samples. (b) Subsequent cycles. (c) Specific capacities $(C / 5$, $\mathrm{Na}$-insertion) upon cycling for different carbons and coulombic efficiency for the templated carbon. All data are obtained at room temperature at $C / 5\left(q=74.4 \mathrm{~mA} \mathrm{~g} \mathrm{C}{ }^{-1}, j \approx 160 \mu \mathrm{A} \mathrm{cm}^{-2}\right)$.

composition of $\mathrm{NaC}_{17}$, i.e. in average 17 carbon atoms are needed to accommodate one sodium atom. To date, similar capacities at room temperature could be only achieved for carbon black at currents as small as $C / 75$ (three cycles reported). ${ }^{14}$ The outstanding capacity of the templated carbon is shown in Fig. 2c. The graph shows the capacity of all samples vs. the number of cycles. As expected, the nonporous graphite reference shows virtually no sodium uptake, with a
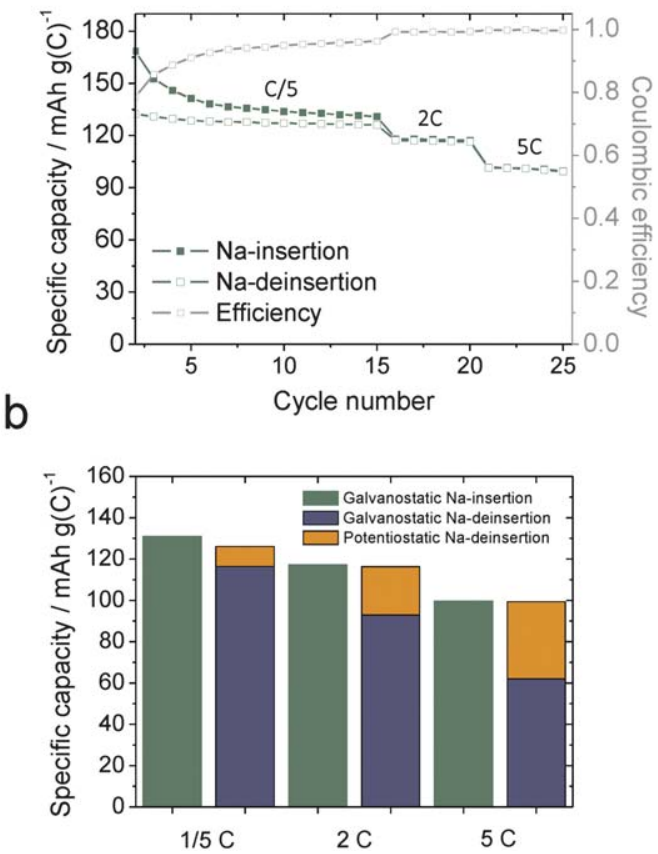

Fig. 3 (a) Rate capability of the templated carbon. (b) Contribution of the potentiostatic step at $1.6 \mathrm{~V}$ to the total charge capacity upon $\mathrm{Na}-$ deinsertion (15th, 20th, and 25th cycle).

capacities well below $5 \mathrm{~mA} \mathrm{~h} \mathrm{~g}$ (no Na plating was observed). The commercial carbons exhibit, despite their different nature and surface areas, quite similar capacities of between $20 \mathrm{~mA} \mathrm{~h} \mathrm{~g}^{-1}$ and $40 \mathrm{~mA}$ $\mathrm{h} \mathrm{g}^{-1}$ (nominal composition between $\mathrm{NaC}_{110}$ and $\mathrm{NaC}_{55}$ ), indicating that higher capacities cannot be simply achieved by enlarging the surface area or increasing the porosity. The templated carbon shows a capacity roughly 4 times as high under identical conditions. The capacity stabilizes upon cycling and reaches a coulombic efficiency of $95.2 \%$ after 20 cycles and $97.9 \%$ after 40 cycles. After 40 cycles, the capacity faded but still reached $80 \mathrm{~mA} \mathrm{~h} \mathrm{~g}^{-1}$ after 125 cycles. The high capacities found for the templated carbon are likely to originate from both (1) the peculiar interconnected pore structure that minimizes the diffusion lengths within the electrode and the carbon matrix and (2) the use of mesophase pitch as carbon precursor, which develops into a well-defined and thus highly conductive carbon microstructure compared to when other carbon precursors are used. By use of such a structure, the kinetic properties are optimized. The exact role of the carbon microstructure (size of the graphene stacks, purity, terminating groups) and porosity (pore size, geometry, connectivity) on the capacity are difficult to assign and are subject to further studies. So far, one can conclude from the present results that the defined macroporosity plays an important role, as none of the commercial carbons exhibits such a feature.

The excellent kinetic properties can also be seen from the rate capability measurements in Fig. 3. Again, the system stabilizes upon prolonged cycling at $C / 5$. At higher currents (2 C and $5 \mathrm{C}$ ) the capacity still exceeds $100 \mathrm{~mA} \mathrm{~h} \mathrm{~g}{ }^{-1}$, while reaching high coulombic efficiencies ( $99.8 \%$ after 25 cycles). The contribution of the potentiostatic step to the total capacity upon Na-deinsertion is shown in Fig. 3b. The potentiostatic step allows the electrode to relax and equilibrate and proves that almost all $\mathrm{Na}^{+}$can be reversibly inserted into the carbon electrode, i.e. a high coulombic efficiency is found and negligible 
irreversible side reactions are present upon cycling. At higher $C$-rates the contribution increases but still the majority of the capacity upon $\mathrm{Na}$-deinsertion is obtained under galvanostatic conditions.

\section{Conclusions}

We demonstrated for the first time that high $\mathrm{Na}$ capacity carbon anode materials with excellent rate capability at room temperature can be achieved by introducing a hierarchical porosity via the nanocasting route. Compared to Li-ion batteries it is needless to say that research on room temperature Na-ion batteries is still in its infancy and several issues such as lowering the degree in irreversible capacity or choice of the right combination of electrodes and electrolytes (plus additives) have to be addressed. However, the present example clearly demonstrates that nanotechnological strategies can be successfully applied in order to significantly improve the performance of electrode materials in new battery systems that are otherwise unsuitable. As there is a large variety of nanostructured carbon materials available (nanotubes, CMK-3, aerogels, etc.), these findings might open new opportunities in the search for suitable materials for room temperature $\mathrm{Na}$-ion batteries.

\section{Acknowledgements}

We thank BASF SE for providing high purity metallic sodium, Timcal Ltd. for providing carbon materials and Mitsubishi Gas Chemical Company for providing mesophase pitch AR.

\section{Notes and references}

1 X. C. Lu, G. G. Xia, J. P. Lemmon and Z. G. Yang, J. Power Sources, 2010, 195, 2431-2442.

2 T. B. Reddy, Linden's Handbook of Batteries, McGraw-Hill, 2010.

3 Y. P. Ma, M. M. Doeff, S. J. Visco and L. C. De Jonghe, $J$. Electrochem. Soc., 1993, 140, 2726-2733.

$4 \mathrm{~K}$. West, B. Zachau-Christiansen, T. Jacobsen and S. Atlung, $J$. Electrochem. Soc., 1985, 132, 3061-3062.

5 Y. Yamada, T. Doi, I. Tanaka, S. Okada and J. Yamaki, J. Power Sources, 2011, 196, 4837-4841.
6 H. M. Liu, H. S. Zhou, L. P. Chen, Z. F. Tang and W. S. Yang, J. Power Sources, 2011, 196, 814-819.

7 D. Kim, S.-H. Kang, M. Slater, S. Rood, J. T. Vaughey, N. Karan, M. Balasubramanian and C. S. Johnson, Adv. Energy Mater., 2011, 1, 333-336.

8 J. S. Kim, H. J. Ahn, H. S. Ryu, D. J. Kim, G. B. Cho, K. W. Kim, T. H. Nam and J. H. Ahn, J. Power Sources, 2008, 178, 852-856.

9 H. T. Zhuo, X. Y. Wang, A. P. Tang, Z. M. Liu, S. Gamboa and P. J. Sebastian, J. Power Sources, 2006, 160, 698-703.

10 J. Sangster, J. Phase Equilib. Diffus., 2007, 28, 571-579.

11 D. A. Stevens and J. R. Dahn, J. Electrochem. Soc., 2001, 148, A803A811.

12 P. Thomas, J. Ghanbaja and D. Billaud, Electrochim. Acta, 1999, 45, 423-430.

13 D. A. Stevens and J. R. Dahn, J. Electrochem. Soc., 2000, 147, 12711273.

14 R. Alcantara, J. M. Jimenez-Mateos, P. Lavela and J. L. Tirado, Electrochem. Commun., 2001, 3, 639-642.

15 P. Thomas and D. Billaud, Electrochim. Acta, 2002, 47, 3303-3307.

16 R. Alcantara, P. Lavela, G. F. Ortiz and J. L. Tirado, Electrochem. Solid-State Lett., 2005, 8, A222-A225.

17 Y. S. Hu, P. Adelhelm, B. M. Smarsly, S. Hore, M. Antonietti and J. Maier, Adv. Funct. Mater., 2007, 17, 1873-1878.

18 A. H. Lu and F. Schuth, Adv. Mater., 2006, 18, 1793-1805.

19 H. Buqa, D. Goers, M. Holzapfel, M. E. Spahr and P. Novak, J. Electrochem. Soc., 2005, 152, A474-A481.

20 M. Winter, K. C. Moeller and J. O. Besenhard, Carbonaceous and Graphitic Anodes, in Lithium Batteries-Science and Technology, Springer, 2003.

21 J. R. Dahn, T. Zheng, Y. H. Liu and J. S. Xue, Science, 1995, 270, 590-593.

22 D. Aurbach, Y. Eineli, B. Markovsky, A. Zaban, S. Luski, Y. Carmeli and H. Yamin, J. Electrochem. Soc., 1995, 142, 2882-2890.

23 D. Aurbach, B. Markovsky, I. Weissman, E. Levi and Y. Ein-Eli, Electrochim. Acta, 1999, 45, 67-86.

24 G. H. Wrodnigg, J. O. Besenhard and M. Winter, J. Electrochem. Soc., 1999, 146, 470-472.

25 S. Yoon, H. Kim and S. M. Oh, J. Power Sources, 2001, 94, 68-73.

26 S. R. Mukai, T. Hasegawa, M. Takagi and H. Tamon, Carbon, 2004, 42, 837-842.

27 F. Beguin, F. Chevallier, C. Vix-Guterl, S. Saadallah, V. Bertagna, J. N. Rouzaud and E. Frackowiak, Carbon, 2005, 43, 2160-2167.

28 D. W. Liu and G. Z. Cao, Energy Environ. Sci., 2010, 3, 1218-1237.

29 L. J. Fu, H. Liu, C. Li, Y. P. Wu, E. Rahm, R. Holze and H. Q. Wu, Solid State Sci., 2006, 8, 113-128.

30 W. M. Lu and D. D. L. Chung, Carbon, 2003, 41, 945-950. 